\title{
On island landscape pattern of forests in Helan Mountain and its cause of formation
}

\author{
DENG Hongbing, WANG Yingming, ZHANG Qiaoxian \& YAN Yan \\ State Key Lab of Systems Ecology, Research Center for Eco-Environmental Sciences, Chinese Academy \\ of Sciences, Beijing 100085, China \\ Correspondence should be addressed to Yan Yan (email: yyyanyan@263.net) \\ Received October 10, 2005; accepted April 12, 2006
}

\begin{abstract}
Based on the spatial information techniques such as RS, GIS, and GPS, the forest landscape patterns in the Helan Mountain, western China, were studied. The Landsat 5 TM data were used to classify the forest landscapes through RS digital cartography, and then, the landscape characteristics and landscape pattern were analyzed quantificationally. Furthermore, through spatial data collection and spatial analysis of the main disturbances in this area, the cause of landscape formation was studied. The results showed that the total 1177 forest landscape patches could be classified into 21 landscape types, and the forest landscape in the Helan Mountain was island pattern, which was encircled by deserta as matrix. The values of landscape diversity index and landscape fragmentation index were 2.61 and 0.43 , respectively. In this area, the landscape pattern was clearly formed and continuously changed in response to geological processes, climate, activities of organisms, forest fire, desertification, human activities and so on. This landscape pattern had an obviously negative effect on the stability and ecosystem services of forests. So, scientific landscape planning and protection should be adopted to improve the sustainability of forest management in this area.
\end{abstract}

Keywords: landscape pattern, island landscape of forest, disturbance, Helan Mountain.

Land is an important and finite resource for most human activities such as settlement, agriculture, forestry, animal husbandry, industry, transportation and recreation. It has been tightly coupled with economic growth. One of the six possible forces driving land use and cover changes is population increase and its level of economy, political structure, affluence, technology, and attitudes and values ${ }^{[1]}$. Population increase causes a sequence of immediate life sustaining needs such as residence space, food and fiber ${ }^{[2]}$. However, due to the finite amount of available land, fast economic development and population growth lead to deforestation and loss of arable land and biodiversity, reduction of 
environmental services, and accelerated urbanization.

Human activities will result in fragmentation of natural landscape, and studying effects of human activities on fragmentation of natural landscape is helpful to resolving the eco-environmental problems ${ }^{[3-9]}$. Forest landscape pattern is the spatial combination of forest landscape elements with different sizes and shapes, and the result of reciprocity of different ecological processes at different scales. It affects energy flow, material flow and species flow of forest ecosystem, and is the important factor in some ecological processes $^{[4-7]}$. The actual forest landscape pattern is formed on the base of natural, social, and economic processes, so, analyzing temporal dynamics of forest landscape pattern can reveal the rules and mechanism of forest landscape succession, forecast the future development of forest landscape and provide the theoretic basis for realizing sustainable utilization of forest resources.

Western China is the region of great importance in ecological construction, and under the condition of develop-the-west strategy of China, studying the status, process, and factors of forest landscape change in this region is useful for ecological construction. There are abundant plant species in the Helan Mountain region, and forests in this region play an important role in providing ecological services. But, what is the forest landscape in this region, what is the cause of the landscape formation, and what is the relationship between human activities and forest landscape? All these questions are essential to the studies on the forests and its landscape in this region, and have higher value in scientific research and ecological construction practice ${ }^{[10-12]}$. So, in this paper, spatial information techniques, such as RS, GIS and GPS, were used to study the characteristics and pattern of forest landscape in the Helan Mountain region, and then, the natural and human factors, which resulted in the forest landscape in this region, were analyzed.

\section{Study area and methods}

\subsection{Study area}

The Helan Mountain is located among the Yinchuan plain, Ningxia and Alashan Plateau, Inner Mongolia, and its geographic location is $38^{\circ} 21^{\prime}-39^{\circ} 22^{\prime} \mathrm{N}$ and $105^{\circ} 49^{\prime}-$ $106^{\circ} 41^{\prime} \mathrm{E}$ (Fig. 1). It is a zonal mountain region with north-south length of about $250 \mathrm{~km}$ and east-west width of about $20-40 \mathrm{~km}$. The average altitude of the Helan Mountain is $2000-3000 \mathrm{~m}$, with the maximum of $3556 \mathrm{~m}^{[10-12]}$. It belongs to the typical continental climate, which is characterized by drought and little precipitation. Disastrous weather often happens, and vegetation has been degraded severely.

\subsection{Data acquisition}

The Landsat 5 TM data in the year 2000 were used as the main data source. Thematic maps included basic relief maps (1:100000, 1:50000, and 1:25000), soil map (1:50000), existing land use map (1:100000), vegetation map, and precipitation map. Attribute data contained regional meteorological data for 40 years, forest inventory data of 1990 and 1995, biodiversity inventory data, and data on social and economic development. Aeronavigation GPS was used to collect spatial data on human activities in field. 


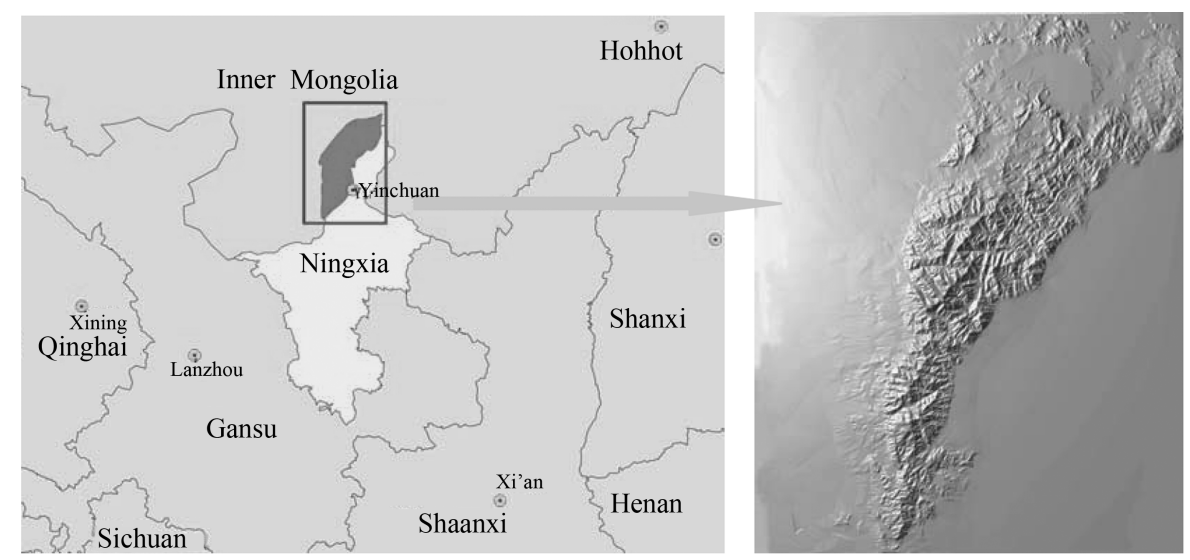

Fig. 1. Study area.

\subsection{Data processing}

Fig. 2 shows the data processing in this research. With the help of different scale relief maps offering ground control points, satellite images on the study area were pre-processed including geometric correction and enhancement. Referencing many thematic maps such as vegetation map, soil map, aerial photograph, investigation data of plot on the ground, and forest inventory database, satellite image interpreter and classification was done. After post-classification processing using minimum units of $1 \mathrm{~km}^{2}$, initial map was

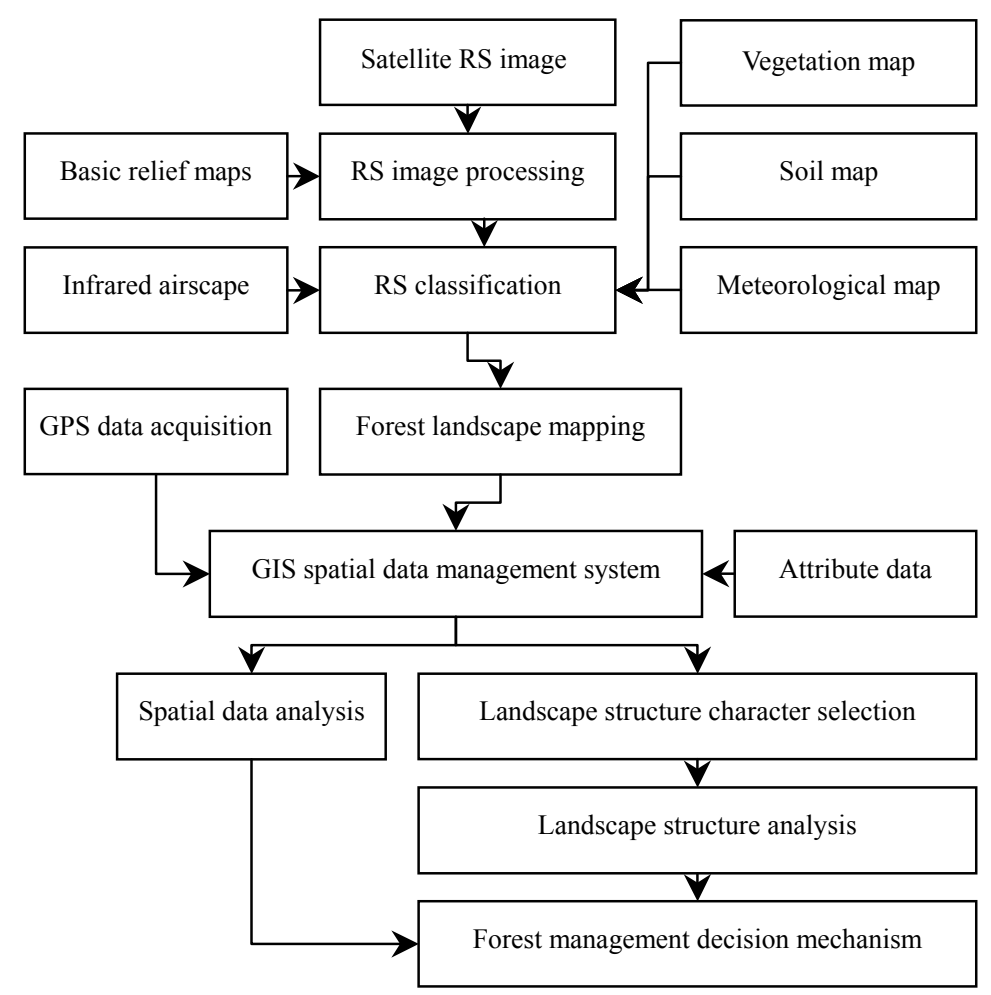

Fig. 2. Sketch map of the data processing in this research. 
generated. Furthermore, the quality of result data was validated through checking topology relationship and the accuracy of attribute of every patch. Finally, different aspect maps, such as vegetation type map, soil map, slope map, aspect map, precipitation map, humidity map, contour map and so on, were used to do data fusion. All of them had the same projection system for overlay and spatial analysis.

\subsection{Landscape index calculation}

Landscape indexes, which included patch amount, average area, perimeter, abundance, degree of fragmentation, and landscape diversity index, were calculated mainly by ArcGIS software and the relative calculating formula ${ }^{[5-7]}$. Among them, landscape diversity index reflects the number and ration of each landscape element, and its calculating formula was

$$
H=-\sum_{k=1}^{m}\left(P_{k}\right) \log _{2}\left(P_{k}\right)
$$

where parameter $P_{k}$ was the area ratio of landscape type $k$ to all landscape types, and parameter $m$ was the amount of the landscape types in the study area.

Degree of fragmentation $(D f)$ was calculated by the formula ${ }^{[5,7]}$ as

$$
D f=\frac{\sum_{k=1}^{m} n_{k}}{A}
$$

where $\sum_{k=1}^{m} n_{k}$ was the total amount of the entire landscape patches, and parameter $A$ was the total landscape area.

\section{Results and analysis}

\subsection{Landscape structure}

There were 21 landscape types in this region (Table 1), and the relative landscape indexes of them were calculated. The results showed that area of deserta, which mainly contained desert steppe, veldt, steppization desert, was $6222.7 \mathrm{~km}^{2}$, accounting for $66 \%$ of the total area. Among the landscape types in this region, deserta had the maximum area, the most complete connectivity, and the strongest effect on the landscape dynamics. So, it could be determined that deserta was the matrix of landscape in this region, and along with the intensification of desertification, the matrix character was increasingly obvious.

Patch abundance reflects the importance and fragmentation of certain landscape type to a certain degree. Among the landscape types in the Helan Mountain, hilly deciduous broadleaved coppice had the highest abundance, and the value was 18.44. Abundance of hilly veldt was the second, and the value was 13.42. Abundance of sub-alpine deciduous coppice was the third, and the value was 11.98. It showed that these three landscape types were distributed widely in this region. In fact, these three landscape types depended on 
Table 1 Landscape types and relative indexes in Helan Mountain

\begin{tabular}{|c|c|c|c|c|c|c|}
\hline Number & Patch type & $\begin{array}{l}\text { Patch } \\
\text { amount }\end{array}$ & $\begin{array}{l}\text { Average area } \\
\left(\mathrm{km}^{2}\right)\end{array}$ & $\begin{array}{l}\text { Perimeter } \\
(\mathrm{km})\end{array}$ & $\begin{array}{l}\text { Abun- } \\
\text { dance }\end{array}$ & $\begin{array}{l}\text { Degree of frag- } \\
\text { mentation }\end{array}$ \\
\hline 1 & Alpine meadow & 17 & 1.13 & 147.29 & 1.44 & 0.89 \\
\hline 2 & Sub-alpine deciduous coppice & 141 & 0.65 & 811.46 & 11.98 & 1.53 \\
\hline 3 & Picea crassifolia forest & 73 & 2.8 & 1128.91 & 6.2 & 0.36 \\
\hline 4 & $\begin{array}{l}\text { Chinese pine- } \\
\text { Picea crassifolia forest }\end{array}$ & 27 & 0.3 & 91.85 & 2.29 & 3.35 \\
\hline 5 & Chinese pine forest & 89 & 0.92 & 685.89 & 7.56 & 1.09 \\
\hline 6 & Juniperus rigida forest & 10 & 0.27 & 32.47 & 0.85 & 1.09 \\
\hline 7 & $\begin{array}{l}\text { Chinese pine-Populus } \\
\text { davidiana forest }\end{array}$ & 16 & 0.47 & 76.06 & 1.36 & 2.11 \\
\hline 8 & $\begin{array}{l}\text { Juniperus rigida- } \\
\text { Ulmus glaucescens forest }\end{array}$ & 82 & 0.8 & 632.25 & 6.97 & 1.26 \\
\hline 9 & $\begin{array}{l}\text { Picea crassifolia- } \\
\text { Populus davidiana forest }\end{array}$ & 103 & 0.62 & 578.73 & 8.75 & 1.61 \\
\hline 10 & $\begin{array}{l}\text { Hilly deciduous } \\
\text { broadleaved coppice }\end{array}$ & 217 & 1.9 & 2307.22 & 18.44 & 0.53 \\
\hline 11 & Ulmus glaucescens forest & 42 & 0.29 & 131.75 & 3.57 & 3.41 \\
\hline 12 & Populus davidiana forest & 44 & 0.3 & 156.07 & 3.74 & 3.28 \\
\hline 13 & Hilly desert steppe & 53 & 14.18 & 1589.63 & 4.5 & 0.07 \\
\hline 14 & Mesa desert steppe & 3 & 950.95 & 1433.39 & 0.25 & 0.01 \\
\hline 15 & $\begin{array}{l}\text { Ephedra rhytidosperma } \\
\text { coppice }\end{array}$ & 7 & 1.83 & 68.82 & 0.59 & 0.55 \\
\hline 16 & Hilly meadow & 8 & 0.57 & 40.44 & 0.68 & 1.75 \\
\hline 17 & Hilly veldt & 158 & 3.65 & 3067.36 & 13.42 & 0.27 \\
\hline 18 & Sabina vulgalis coppice & 13 & 0.48 & 62.54 & 1.1 & 2.08 \\
\hline 19 & Steppization desert & 26 & 77.62 & 1884.59 & 2.21 & 0.01 \\
\hline 20 & Mine field & 8 & 1.61 & 82.97 & 0.68 & 0.62 \\
\hline 21 & Farmland & 40 & 55.36 & 960.14 & 3.4 & 0.02 \\
\hline Total & & 1177 & 8.35 & 18541.2 & 100 & 0.12 \\
\hline
\end{tabular}

unique habitat, and the suitable habitat was small and abundant, so their abundances were high.

Mesa desert steppe and steppization desert had the minimum fragmentation degree as 0.01 , and that of farmland, which was 0.02 , was the second. It showed that these three landscape types were composed of big patch mainly. Fragmentation degrees of Ulmus glaucescens forest (3.41), Chinese pine-Picea crassifolia forest (3.35), and Populus davidiana forest (3.28) were the top three, and other forest types also had relatively high fragmentation degree. It showed that forest in this region was under high fragmentation. Generally, landscape fragmentation was related to disturbance closely. In this region, disturbance resulted in degeneration of forest vegetations, and it was the cause of high forest landscape fragmentation. Along with the habitat fragmentation, the spatial distribution of forests showed an island landscape (Figs. 3 and 4).

By calculation, the value of landscape diversity index was 2.61 and relatively high. The Helan Mountain is located in the boundary between temperate grassland area and desert area, with the obvious transitional character. It showed that this region was important in ecological protection. But fragmentation of forest landscape restricts the forests' ecological protection function, so it is important to study the causes of forest island landscape forming and to adopt reasonable measures in the ecological practice. 


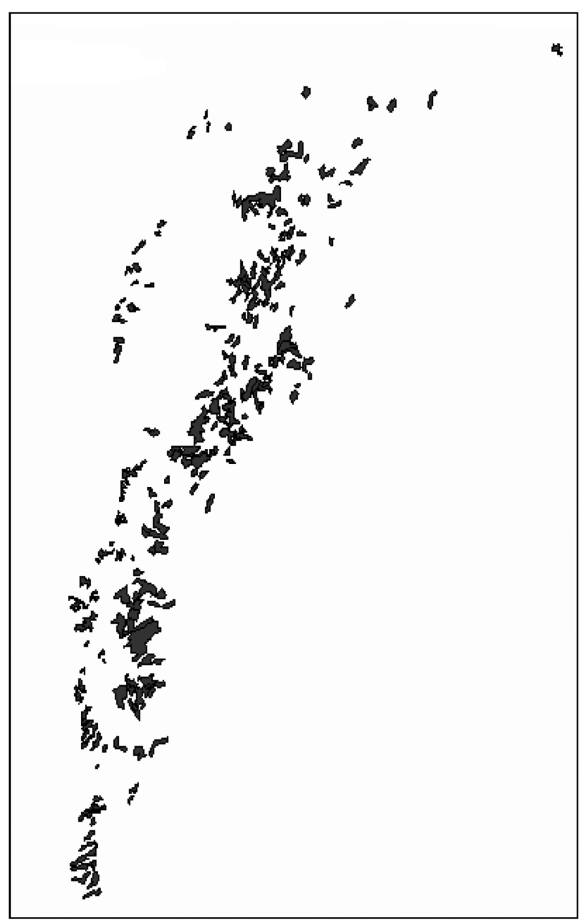

Fig. 3. Mixed forest landscape.

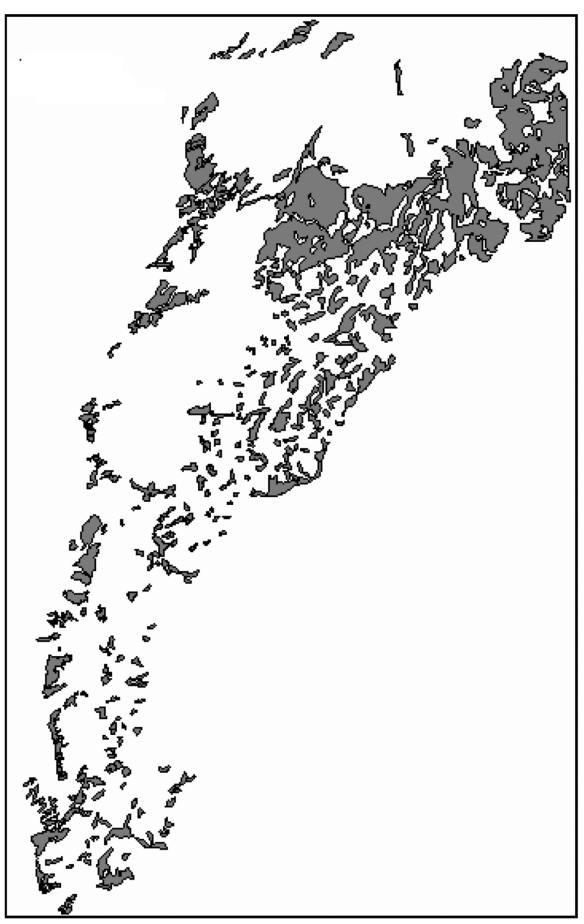

Fig. 4. Broadleaved forest landscape.

\subsection{Causes of forest island landscape forming}

In general, landscape forming is caused by natural factors and human disturbance. The major natural factors are geological processes, climate, and soil. Geological features produced by geological processes such as volcanism, sedimentation, and erosion, provide a primary source of landscape structure. Climate, including rainfall and temperature, is also a major determinant of landscape structure in the Helan Mountain. Furthermore, distinctive soils contribute to vegetative patches in this region (Fig. 5).

Fig. 5 shows all the natural factors influencing the whole landscape forming in this region. For the forming of forest island landscape, desertification is a very important factor. Except the east of Helan Mountain forest area being Yinchuan plain, its south, north, and west are Tenggeli desert, Wulanbuhe desert, and Alashan plateau, respectively, and in these areas, the zonal vegetation is desert steppe or steppization desert. The peripheral desert is invading the forest area of Helan Mountain, and for example, the dune of Tenggeli desert expands $0.6-6.2 \mathrm{~m}$ per year southeastward. In the east and west sides, there were 133 canals, and most of them were seasonal due to drought ${ }^{[13]}$. So, the dune could be removed to the low hilly area along the canals. In recent years, sandstorm often happened, and it was the severest in the east foot and pass of Helan Mountain. The strong wind caused soil erosion and tree falling, which was harmful to tree growth, and the vegetation on the stoss slope was destroyed severely ${ }^{[13]}$.

Besides the natural factors, human disturbances, such as excess firewood gathering, overgrazing and urbanization, are the main causes of desertification. 


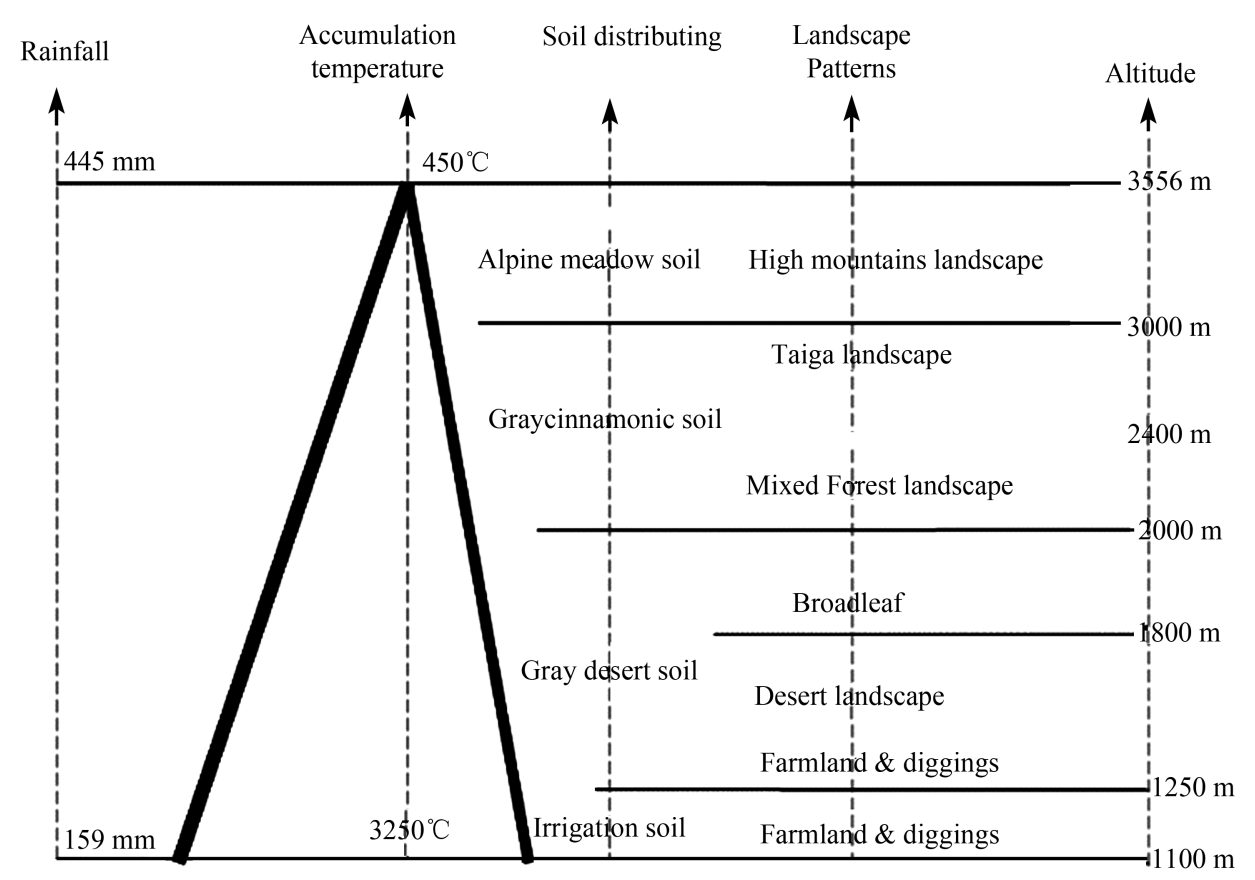

Fig. 5. Natural factors influencing landscape forming in the Helan Mountain.

The landscape and vegetation in the Helan Mountain has been influenced by human beings for thousands year. Along with the human activities being increasingly frequent, the forest vegetation was gradually moved upward. On the east slope of Helan Mountain, compared to the west slope, there was high population and huge demands of timber, so the forest on the east slope was destroyed more severely. By field investigation, it showed that Picea crassifolia forest was distributed at higher than $2000 \mathrm{~m}$ on the east slope, and it could be found at the elevation of $1800 \mathrm{~m}$ on the west slope. Uncontrolled cutting and excess firewood gathering resulted in the destruction of forest in the low and middle hilly area, and made the tree line upward from 1300 to $1800 \mathrm{~m}$. So, the landscape pattern was also changed.

Overgrazing had a far-reaching effect on the landscape of Helan Mountain. According to investigation, Chinese pine forest in the area under frequent activities of goat was in extremely bad status. In the 1960 s, there were only 20 thousand goats on the east slope, while there were more than 180 thousand goats in 1990. The speed of goat increase has been especially accelerated after the performance of "Reform and Opening-up" policy. In 1985, there were about 440 thousand goats in Yinchuan and Shizuishan at the east slope of Helan Mountain; during June - October, there were annually about 220 thousand goats grazing on the Helan Mountain; there were 520 herds (about 137.8 thousand) of goat perennially gazed on the Helan Mountain, and 1564 grazier. By calculation, in the 36 years from 1949-1985, there has been more than $113 \mathrm{~km}^{2}$ of pine forest destroyed, for gazing, nursing a fire, warming kang and cooking. These destroyed pine forest is mainly located in low mountain zones at the altitude ranging from 1300 to $1600 \mathrm{~m}$. The effects of overgrazing are influencing natural regeneration and vegetation, producing serious 
vegetation degeneration and severe soil and water losses.

Urbanization was also an important human disturbance in this region, and the development of peripheral industrial area influenced the landscape pattern. According to statistic data, in the recent 50 years, the amount of factories has reached more than 400, most of which belong to wood processing. Quite a few roads and mine construction were newly built, which caused mountain sinking and landslide. All these resulted in severe destruction of the vegetation and natural landscape.

\section{Conclusions and strategies}

In the Helan Mountain, the landscape pattern had high spatial heterogeneity and unique characters in patch amount, area, shape, and spatial combination. There were 21 landscape types in this region, and deserta, which mainly contained desert steppe, veldt, and steppization desert, was the matrix of landscape in this region. Hilly deciduous broadleaved coppice, hilly veldt, and sub-alpine deciduous coppice had higher abundance due to their unique demand for habitats. Forest concluded Picea crassifolia forest, Chinese pine-Picea crassifolia forest, Chinese pine forest, Juniperus rigida forest, Chinese pine-Populus davidiana forest, Juniperus rigida-Ulmus glaucescens forest, Picea crassifolia-Populus davidiana forest, Ulmus glaucescens forest, and Populus davidiana forest, compared to other landscape types, their fragmentation degrees were higher, and the spatial distribution of forests showed island landscape. This island landscape of forest was easy to be fluctuated and had the imperfect function, thus resulting in the weak ability against natural disasters. Besides geological processes, climate and soil, human disturbances were the main factors in this region. The existing landscape pattern had an obviously negative effect on the stability and ecosystem services of forests. So, scientific landscape planning and protection should be adopted to improve the sustainability of forest management in this area.

So, according to the current status and the cause of the landscape in this region, some corresponding strategies could be offered: (1) Before policy-making and construction, the scientific design with nature is necessary. (2) Desertification prevention is the main task of the ecological constructions in this region. (3) To prohibit grazing in some places properly, and to protect infancy trees. (4) Reforestation and building ecological corridor; enlarging the protected region and the heartland of patches. (5) To coordinate the relationship between development and protection.

Acknowledgements This work was supported by the Chinese Academy of Sciences (Grant Nos. KZCX 3-SW-423 and KZCX 3-SW-438) and the National Natural Science Foundation of China (Grant Nos. 70325002 and 70403014)

\section{References}

1 Xie Y C, Yu M, Tian G J, et al. Socio-economic driving forces of arable land conversion: a case study of Wuxian City, China. Glob Environ Change (in Chinese), 2005, 15: 238-252

2 Uusiwuori J, Lehto E, Palo M. Population income and ecological conditions as determinants of forest area variation in the tropics. Glob Environ Change, 2002, 12(2): 313-323 
3 Li X B. Driving Forces of Arable Land Conversion in China, IIASA IR-97-076, 1997

4 Fu B J, Chen L D. Agricultural landscape spatial pattern analysis in the semi-arid hill area of the Loess Plateau, China. J Arid Environ (in Chinese), 2000, 44 (3): 291-303

5 Fu B J, Chen L D, Ma K M. Principle and Application of Landscape Ecology (in Chinese). Beijing: Science Press, 2001

6 Wu J G. Landscape Ecology: Pattern, Process, Scale and Hierarchy (in Chinese). Beijing: Higher Education Press, 2000

7 Xiao D N. Landscape Ecology: Theory, Method and Application (in Chinese). Beijing: China Forestry Publishing House, 1991

8 Chen L D, Fu B J. Analysis of impact of human activity on landscape structure in yellow river delta: a case study of Dongying region. Acta Ecol Sin (in Chinese), 1996, 16(4): 337-344

9 Zhou H F, Ma K M, Fu B J. Analysis of the impacts of human activities on landscape patterns in Dongling Mountain area of Beijing. J Nat Resour (in Chinese), 1999, 14(2): 117-122

10 Di W Z. Fibrovascular plant in Helanshan Mountain (in Chinese). Xi'an: Northwest University Press, 1986

11 Geng K, Shan P F. Yinchuan Region: Present, Now and Future (in Chinese). Beijing: Mapping Press, 1992

12 Tang L J, Dai X Z, Mei S G. Ningxia Forest (in Chinese). Yinchuan: Ningxia People’s Press, 1988

13 Ningxia Development and Reform Commission. General Situation of Ningxia (in Chinese). Yinchuan: Ningxia People's Press, 1988 